\title{
FAKTOR-FAKTOR YANG MEMENGARUHI GETOK TULAR PADA USAHA RESTORAN WARALABA DI JAKARTA
}

\author{
Glisina Dwinoor Rembulan* \\ Program Studi Teknik Manajemen Industri, Universitas Bunda Mulia
}

\begin{abstract}
In 2017 the number of franchise turnover in Indonesia reached 200 trillion rupiah with a composition of 65\% contributed by foreign franchises and 35\% came from local franchises. The food and beverage industry sector also contributes 80 percent of the total franchise turnover in Indonesia. Based on data from the Ministry of Tourism of Indonesia, restaurant businesses with medium and large scale increased in number even though based on the percentage of growth slowed down. From 2008-2011 the restaurant business experienced an increase of 600 units of restaurants. This explains that restaurant businesses, especially food and beverages, have a high appeal to people's consumption choices. Various factors of attraction and weakness of a franchise restaurant is not uncommon to be a discussion and recommendation of the community either directly or online media. This study aims to measure whether influenza is influenced by the quality of food, the quality of restaurant officers, and the appearance of the restaurant. This study used multiple regression and SPSS 24 to analyze the data. The result of this research explains that partially word of mouth is not influenced by the quality of food, the quality of the restaurant officer, and the appearance of the restaurant. Simultaneously, these factors have an effect on the word of mouth. The use and socialization of the voting system and comments on the factors in this study can help the restaurant franchise business in the formation and dissemination of public spirits.
\end{abstract}

Keywords: Restaurant, franchise, word of mouth

\begin{abstract}
ABSTRAK
Tahun 2017 jumlah omset waralaba di Indonesia mencapai Rp. 200 triliun dengan komposisi 65\% disumbangkan oleh waralaba asing dan $35 \%$ berasal dari waralaba lokal. Sektor industri makanan dan minuman juga menyumbangkan angka sebesar $80 \%$ dari total omset waralaba di Indonesia. Berdasarkan data Kementerian Pariwisata Indonesia, usaha restoran dengan skala menengah dan besar mengalami kenaikan secara angka walaupun berdasarkan persentase pertumbuhannya melambat. Dari tahun 2008-2011 usaha restoran mengalami penambahan jumlah sebanyak 600an unit restoran. Hal ini menjelaskan bahwa usaha restoran khususnya makanan dan minuman memiliki daya tarik yang tinggi pada pilihan konsumsi masyarakat. Berbagai faktor daya tarik dan kelemahan suatu restoran waralaba tidak jarang menjadi pembicaran dan rekomendasi masyarakat baik secara langsung maupun media daring. Penelitian ini bertujuan untuk mengukur apakah getok tular dipengaruhi oleh kualitas makanan, kualitas petugas restoran, dan kuliatas tampilan restoran. Penelitian ini menggunakan regresi berganda dan SPSS 24 untuk menganalisis data. Hasil dari penelitian ini menjelaskan bahwa secara parsial getok tular tidak dipengaruhi oleh kualitas makanan, kualitas petugas restoran, dan kuliatas tampilan restoran. Secara simultan faktor-faktor tersebut memberikan pengaruh terhadap getok tular. Penggunaan dan sosialiasi sistem voting dan komentar terhadap faktor-faktor dalam penelitian ini dapat membantu usaha waralaba restoran dalam pembentukan dan penyebaran getok tular ke masyarakat.
\end{abstract}

Kata Kunci: Restoran, waralaba, getok tular

\section{Latar Belakang \\ Kementerian Perindustrian pada} triwulan III 2017 menjelaskan bahwa industri makanan dan minuman mengalami kenaikan sebesar $4 \%$ dibanding pada periode yang sama tahun 2016 (Kurniawan, 2017). Berdasarkan laporan tersebut digambarkan pula bahwa kontribusi industri makanan dan minuman terhadap Pendapatan Domestik Bruto (PDB) sebesar $6,21 \%$. Hal ini mengartikan juga bahwa industri makanan dan minuman dapat menjadi salah satu sektor andalan pertumbuhan ekonomi di Indonesia.

Dalam laporan yang lain Kementerian Perindustrian menjelaskan bahwa dari aspek

* email: grembulan@bundamulia.ac.id 
tingkat serapan tenaga kerja, pada periode Januari-September 2017 industri makanan dan minuman berhasil menyumbang angka sebesar 21,34\% atau sebanyak 3.316.168 orang (Faizal, 2017). Melihat data tersebut paling tidak terdapat indikasi bahwa pertumbuhan pada sektor industri makanan dan minuman yang memeiliki serapan tenaga kerja yang cukup tinggi diharapkan juga mampu memberikan pengalaman kepada para karyawan yang dikemudian hari memungkinkan untuk membuka usaha di sektor industri makanan dan minuman seperti restoran.

Berdasarkan data Kementerian Pariwisata Indonesia, usaha restoran dengan skala menengah dan besar mengalami kenaikan secara angka walaupun persentase pertumbuhannya melambat. Dari tahun 20082011 usaha restoran mengalami penambahan jumlah sebanyak 600an unit restoran (BPS, 2014).

Tabel 1. Perkembangan Usaha Restoran Berskala Menengah dan Besar 2007-2011

\begin{tabular}{cccc}
\hline Tahun & Jumlah & $\begin{array}{c}\text { Pertumbuhan } \\
(\boldsymbol{\%})\end{array}$ & $\begin{array}{c}\text { Serapan Tenaga } \\
\text { Kerja (rata- } \\
\text { rata;orang) }\end{array}$ \\
\hline 2008 & 2.235 & 38,39 & 27 \\
\hline 2009 & 2.704 & 20,98 & 27 \\
\hline 2010 & 2.916 & 7,84 & 27 \\
\hline 2011 & 2.977 & 2,09 & 28 \\
\hline \multicolumn{3}{c}{ Sumber: Kemenpar (2014) }
\end{tabular}

Berdasarkan data di atas dalam empat tahun jumlah restoran terus mengalami peningkatan dengan serapan tenaga kerja 27 orang. Hal ini menjelaskan juga bahwa keberadaan restoran masih menjadi kebutuhan bagi masyarakat khususnya di kota-kota besar yang memiliki jumlah penduduk besar. Secara spesifik, beberapa provinsi dengan jumlah penduduk besar di Indonesia mengalami peningkatan jumlah usaha restoran yang cukup signiifkan. Kontribusi jumlah tersebut masih dominan berasal dari provinsi-provinsi yang berada di pulau Jawa.

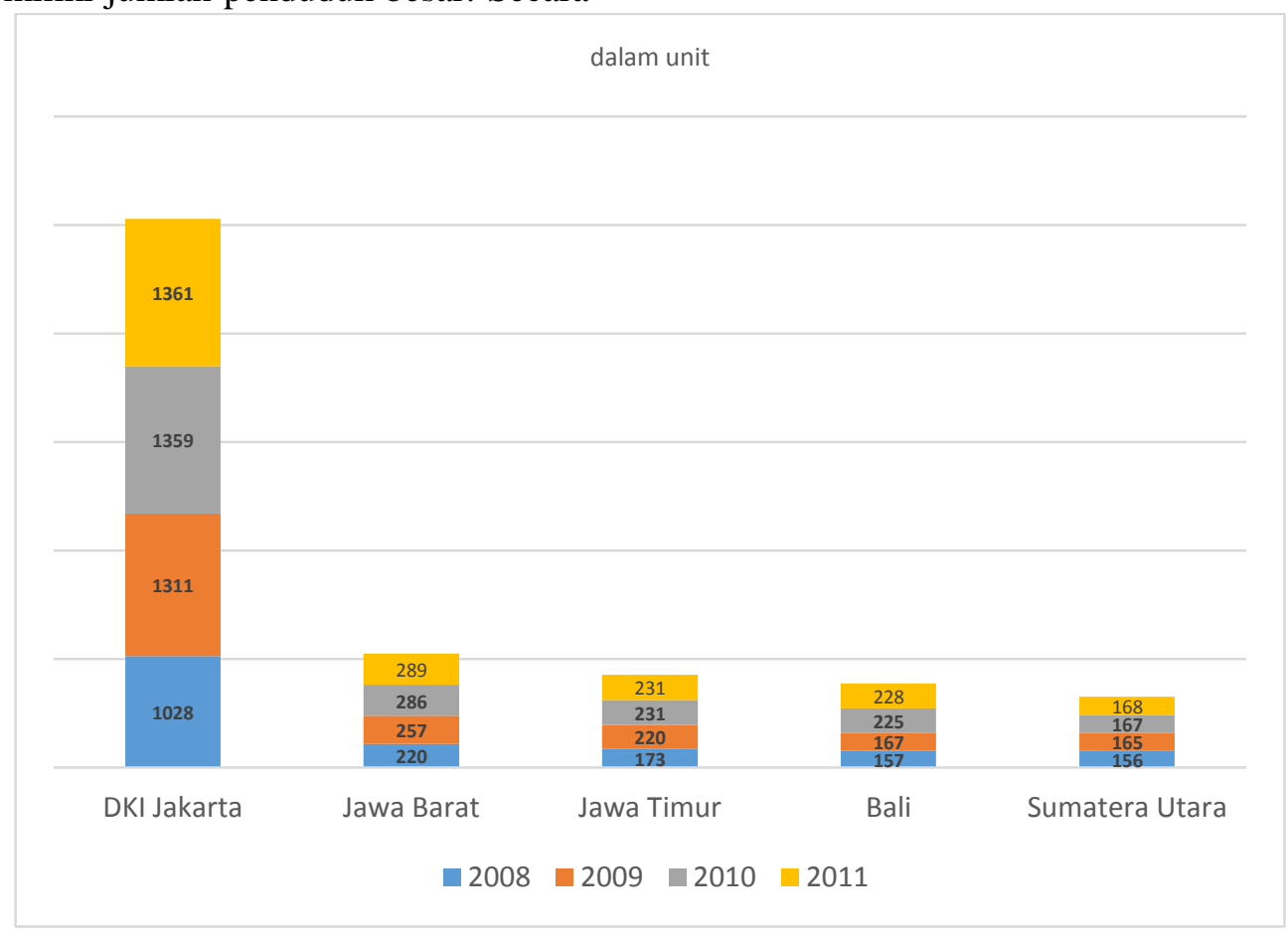

Gambar 1. Perkembangan Usaha Restoran Berskala Menengah dan Besar Menurut Provinsi 2008-2011 Sumber: Kemenpar (2014) 
Peningkatan jumlah usaha restoran di atas berasal dari berbagai bentuk restoran baik restoran yang memang asli Indonesia ataupun yang berasal dari luar Indonesia. Salah satu dari ragam jenis restoran tersebut salah satu penyumbang angka terbesar rasanya memang berasal dari restoran yang berbentuk franchise atau waralaba. Hal yang mendasari jenis restoran jenis ini berkembang dengan pesat adalah sudah adanya sistem manajemen yang jelas dan teratur yang bisa diikuti oleh pengusaha yang membeli lisensi waralaba restoran tersebut. Ketua Umum Perhimpunan Waralaba dan Lisensi Indonesia, Levita Ginting Supit pernah menjelaskan bahwa pada 2017 jumlah omset waralaba di Indonesia mencapai Rp. 200 triliun dengan komposisi $65 \%$ disumbangkan oleh waralaba asing dan 35\% berasal dari waralaba lokal (Yasa, 2018). Sektor industri makanan dan minuman juga menyumbangkan angka sebesar $80 \%$ dari total omset waralaba di Indonesia (beritasatu, 2017). Hal ini menjelaskan bahwa usaha restoran khususnya makanan dan minuman memiliki daya tarik yang tinggi pada pilihan konsumsi masyarakat.

Peningkat jumlah restoran dan jumlah kontribusi omset yang besar bukan tidak mungkin menjadikan sektor ini menjadi daya tarik untuk membentuk wirausaha-wirausaha baru. Direktur Utama Lembaga Pengelola Dana Bergulir (LPDB)-KUMKM menjelaskan bahwa bisnis waralaba dianggap sektor yang paling cepat membentuk wirausaha (beritasatu, 2012). Menurut Menteri Koperasi dan Usaha Kecil dan Menengah (UKM) Anak Agung Gede Ngurah Puspayoga menggambarkan bahwa pertumbuhan wirausaha di Indonesia semakin meningkat dengan rasio 3,1 persen dari 225 juta jiwa penduduk (Fauzi, 2017). Hal ini menjelaskan bahwa pemerintah menunjukkan keseriusannya dalam tetap menjaga iklim persaingan industri usaha makanan dan minuman sekaligus berupaya untuk mendorong terbentuknya wirausahawirausaha baru di sektor usaha ini.

Dalam kaitannya pada upaya mendorong pembentukan wirausaha-wirausaha baru, peran perguruan tinggi dapat menjadi titik awal dan sentral sumber terbentuknya wirausaha baru. Hal ini dilakukan untuk meningkatkan rasio wirausaha di Indonesia dan sekaligus dalam rangka mengejar ketertinggalannya dengan negara-negara lain seperti Malaysia sebesar 5\%, Singapura 7\%, Amerika Serikat 14\%, Cina 11\% dan Jepang 10\% (Julianto, 2017). Peran perguruan tinggi dapat mengupayakan tersedia materi kompetensi dalam kewirausahaan, seperti peningkatan kapasitas kewirausahaan dan pelatihan kewirausahaan. Penguasaan akan kompetensi tersebut diharapkan tidak hanya membentuk mental wirausaha-wirausaha baru namun juga dapat memahami bagaimana menjalankan usaha restoran.

Restoran dengan tipe waralaba jauh lebih memudahkan pengusahanya dalam operasionalisasi usaha restorannya. Sistem dukungan manajemen dan alat pemasaran juga tidak jarang sudah diatur dan disediakan untuk pengusaha restoran berbentuk waralaba walau pun persaingan tetap selalu ada untuk sektor usaha ini. Industri restoran memiliki tingkat persaingan yang tinggi dan cenderung dinamis karena diharuskan mampu dalam menarik pengunjung baru, mempertahankan pelanggan sekaligus dapat memahami keinginan, kebutuhan dan persepsi pelanggan (Jalilvand, Salimipour, Elyasi, \& Mohammadi, 2017). Persepsi pelanggan yang diharapkan terbentuk diharapkan bersifat positif agar dampak yang baik secara berkelanjutan dapat tercipta. Hal ini sejalan dengan Lloyd, Henry, \& Thyne (2011) dimana bentuk getok tular yang diharapkan adalah getok tular yang baik dimana terciptanya rekomendasi dan komunikasi yang positif.

Getok tular juga diakibatkan dari respon secara emosional dari pengunjung ketika makan di suatu restoran (Ha \& Jang, 2010). Ryu \& Han (2010) dengan penelitiannya menungkapkan bahwa getok tular disebabkan oleh faktor-faktor kualitas makanan seperti kelezatan, nilai gizi, dan daya tarik secara tampilan. Selain itu faktor kulitas fisik restoran seperti desain, dekorasi pada sisi interior, sentuhan tambahan suara musik, dan pencahayaan juga memberikan dampak pada terbentuknya getok tular. Ragam tipe restoran baik restoran cepat saji maupun berkelas akan membentuk getok tular apabila memiliki 
kualitas pada makanan dan layanan serta suasana yang ada di restoran tersebut (Bujisic, Hutchinson, \& Parsa, 2014). Yim, Lee, \& Kim (2014) menjelaskan bahwa getok tular dipengaruhi oleh beberapa faktor seperti lokasi restoran, variasi menu makanan, fasilitas parkir, tipe restoran waralaba, dan jumlah ulasan di media daring seperti blog. (Jeong \& Jang, 2011) juga menjelaskan bahwa kualitas makanan yang disajikan restoran memiliki pengaruh positif terhadap terbentuknya getok tular yang baik. Jalilvand, Salimipour, Elyasi, \& Mohammadi (2017) menjelaskan bahwa getok tular dibentuk oleh kualitas makanan, kualitas interaksi dari petugas restoran, kualitas fisik restoran, dan nilai keuntungan makan dengan biaya yang dikeluarkan di suatu restoran.

\section{Identifikasi Masalah}

Identifikasi masalah dalam penelitian ini adalah sebagai berikut:

1. Getok tular dalam usaha restoran waralaba dipengaruhi oleh faktorfaktor apa saja dalam penelitian ini.

2. Diantara faktor-faktor yang memberikan pengaruh terhadap getok tular, faktor-faktor apa saja yang merupakan faktor dominan yang memengaruhi getok tular.

3. Berdasarkan faktor-faktor yang dominan tersebut, bagaimana pendekatan dalam pertimbangan membentuk usaha (berwirausaha) restoran waralaba.

\section{Tujuan dan Manfaat Penelitian}

Tujuan penelitian ini adalah untuk:

1. Mengetahui faktor-faktor apa saja yang memengaruhi getok tular pada usaha restoran berbentuk waralaba di Jakarta

2. Mengetahui faktor-faktor dominan apa saja yang memengaruhi getok tular pada usaha restoran berbentuk waralaba di Jakarta
3. Mengetahui bagaimana pendekatan dalam pertimbangan membentuk usaha (berwirausaha) restoran waralaba berdasarkan faktor-faktor dominan yang memberikan pengaruh

\section{METODE PENELITIAN}

Jenis Penelitian

Metode kuantitatif digunakan dalam penelitian ini dan menggunakan analisis regresi berganda (multiple regression). Penelitian kuantitatif merupakan penelitian yang menggunakan data berbentuk angka sebagai bagian dari alat untuk menganalisis informasiinformasi yang ada dalam penelitian ini.

\section{Pengumpulan Data}

Kuesioner digunakan untuk mengumpulkan data dari responden. Karakter responden dalam penelitian ini adalah orangorang yang memiliki pengalaman makan dan minum pada restoran waralaba di DKI Jakarta. Kuesioner dibentuk dari konstruk yang ada pada tabel operasional yang selanjutnya dibuat kedalam item dengan pilihan sebanyak 5 pilihan jawaban yaitu Sangat Setuju, Tidak Setuju, Netral, Setuju, dan Sangat Setuju. Karakter responden ini dipilih karena hasil yang diharapkan dalam penelitian ini adalah berdasarkan pengalaman responden. Selain itu juga pengalaman dibutuhkan untuk memberikan penilaian objektif terutama pada faktor-faktor yang berkaitan dengan kualitas.

\section{Teknik Analisis Data}

Penelitian ini menggunakan model regresi berganda dengan SPSS 24 sebagai alat untuk mengolah datanya. Analisis dalam penelitian ini akan dilakukan secara parsial dan simultan pada faktor gayut dan bebas. Faktorfaktor gayut dan bebas yang digunakan dalam penelitian ini digambarkan pada tabel operasional berikut. 
Tabel 2. Operasionalisasi Kosntruk Penelitian

\begin{tabular}{|c|c|c|}
\hline Peubah & Indikator & Peneliti/Sumber \\
\hline \multirow[t]{5}{*}{ Kualitas Makanan } & Menarik secara fisik & \multirow{5}{*}{$\begin{array}{l}\text { Namkung \& Jang, } \\
\text { (2007) }\end{array}$} \\
\hline & Menu yang bervariasi & \\
\hline & Pilihan menu sehat & \\
\hline & Kesegaran makanan & \\
\hline & Kesesuian temparatur penyajian makan & \\
\hline \multirow[t]{4}{*}{ Kualitas restoran } & Daya tarik eksterior restoran & \multirow{4}{*}{ Meng \& Elliott (2008) } \\
\hline & Area makan yang menarik & \\
\hline & Unsur sentuhan musik di restoran & \\
\hline & Kebersihan restoran & \\
\hline Kualitas Petugas & Adanya interaksi antara petugas restoran dengan & \multirow{4}{*}{$\begin{array}{l}\text { Vesel \& Zabkar } \\
\text { (2009) }\end{array}$} \\
\hline \multirow[t]{3}{*}{ Restoran } & pengunjung & \\
\hline & Keramahtamahan petugas restoran & \\
\hline & Petugas restoran yang responsif & \\
\hline \multirow[t]{3}{*}{ Getok Tular } & Menceritakan hal positif tentang restoran & \multirow{3}{*}{$\begin{array}{l}\text { Jalilvand, Samiei, } \\
\text { Dini, \& Yaghoubi, } \\
\text { (2012) }\end{array}$} \\
\hline & Merekomendasikan kepada orang lain & \\
\hline & $\begin{array}{l}\text { Mendorong orang lain untuk memilih restoran } \\
\text { tersebut }\end{array}$ & \\
\hline
\end{tabular}

Sumber: data primer

\section{HASIL DAN PEMBAHASAN}

\section{Karakteristik Responden}

Berdasarkan pengumpulan data, maka dapat dijelaskan bahwa responden dalam penelitian ini adalah sebagai berikut:
Responden dalam penelitian ini terdiri dari 12 orang laki-laki $(31,6 \%)$ dan 26 orang perempuan $(68,4 \%)$. Angka ini menjelaskan bahwa responden dalam penelitian ini lebih banyak berasal dari responden dengan gender perempuan.

\section{Tabel 3. Tabel Karakteristik Responden - Gender Gender}

\begin{tabular}{llr|r} 
& & Frequency & \multicolumn{1}{c}{ Percent } \\
\hline \multirow{7}{*}{ Valid } & Laki-laki & 12 & 31,6 \\
\cline { 2 - 4 } & Perempuan & 26 & 68,4 \\
\cline { 2 - 4 } & Total & 38 & 100,0 \\
\hline
\end{tabular}

Sumber: data primer dengan SPSS 24, $\mathrm{n}=38$

Penelitian ini ditunjukkan dengan responden dengan karakter usia muda yang dijelaskan oleh respoden yang memiliki usia
19-20 tahun sebanyak 20 orang $(52,6 \%)$, usia 21-22 tahun sebanyak 13 orang $(34,2 \%)$ dan usia 23-24 tahun (5\%).

Tabel 4. Tabel Karakteristik Responden - Umur

\begin{tabular}{crr|r}
\multicolumn{2}{c}{ Umur } \\
\multicolumn{3}{c}{ Frequency } & \multicolumn{1}{c}{ Percent } \\
\hline Valid & $19-20$ tahun & 20 & 52,6 \\
\cline { 2 - 4 } & $21-22$ tahun & 13 & 34,2 \\
\cline { 2 - 4 } & $23-24$ tahun & 5 & 13,2 \\
\cline { 2 - 4 } & Total & 38 & 100,0 \\
\hline \multicolumn{2}{l}{ Sumber: data primer dengan SPSS $24, \mathrm{n}=38$}
\end{tabular}


Penelitian ini juga mengukur mengenai restoran waralaba favorit responden. Berdasarkan hasil yang diolah, restoran waralaba KFC dan Mc Donald menjadi resotran waralaba favorit dengan angka 18 orang $(47,4 \%)$ dan 16 orang $(42,1)$. Kedua restoran ini memang sudah memiliki gerai di banyak titik khususnya di DKI Jakarta. Ditambah lagi, konsep kenyamanan bagi pengunjung berusia muda sudah semakin ditingkatkan sehingga membuat persepsi bahwa restoran waralaba ini dapat menjadi tempat berkumpul untuk pengunjung dengan karakter usia muda dengan berbagai tujuan utama (misal: berkumpul, mengerjakan tugas, dan sebagainya).

\section{Tabel 5. Tabel Karakteristik Responden - Restoran Waralaba Favorit Restoran Franchise}

\begin{tabular}{llr|r} 
& & \multicolumn{1}{c}{ Frequency } & \multicolumn{1}{c}{ Percent } \\
\hline Valid & 18 & 47,4 \\
\cline { 2 - 4 } & KFC & 16 & 42,1 \\
\cline { 2 - 4 } Mc Donald & 1 & 2,6 \\
\hline Burger King & 1 & 2,6 \\
\hline Pizza Hut & 1 & 2,6 \\
\hline A\&W & 1 & 2,6 \\
\hline Starbucks & 38 & 100,0 \\
\hline Total & 38 &
\end{tabular}

Sumber: data primer dengan SPSS 24, $\mathrm{n}=38$

Penelitian ini mencoba untuk mengukur pengeluaran pembeli restoran waralaba di atas. Sebanyak 13 orang $(34,2 \%)$ responden bersedia mengeluarkan uang sebanyak Rp. 75.001 - Rp. 100.000 untuk sekali kunjungan di restoran waralaba tersebut.
Kemudian diikuti pengeluaran di atas $\mathrm{Rp}$. 100.000 yaitu sebanyak 10 orang (26,3\%). Dan respoden yang memilih kesediaan untuk mengeluarkan uang per kunjungan ke restoran waralaba tersebut sebanyak 9 orang $(23,7 \%)$.

Tabel 6. Tabel Karakteristik Responden - Pengeluaran Membeli Pengeluaran yang biasanya anda habiskan dalam satu kali kunjungan

\begin{tabular}{llr|r} 
& \multicolumn{2}{c|}{ Frequency } & \multicolumn{1}{c}{ Percent } \\
\hline Valid & di bawah Rp. 50.000 & 9 & 23,7 \\
\cline { 2 - 3 } & Rp. 75.001 - Rp. 100.000 & 13 & 34,2 \\
\hline di atas Rp. 100.000 & 10 & 26,3 \\
\hline 4 & 6 & 15,8 \\
\hline Total & 38 & 100,0 \\
\hline
\end{tabular}

Sumber: data primer dengan SPSS 24, $\mathrm{n}=38$

\section{Uji Validitas dan Reliabilitas}

Tabel reliabilitas menujukkan bahwa item yang digunakan dalam penelitian ini dapat dikatakan handal. Hal ini dilihat dari nilai Cronbach's Alpha yang berada di atas 0,6.

Tabel 3. Tabel Kehandalan

\section{Reliability Statistics}

\begin{tabular}{r|r|r} 
Cronbach's Alpha & Cronbach's Alpha Based on Standardized Items & N of Items \\
\hline, 884 &, 896 & 14 \\
\hline
\end{tabular}

Sumber: data primer dengan SPSS 24, $\mathrm{n}=38$ 
Tabel Item-Total Statistic

menunjukkan bahwa data yang digunakan dalam penelitian ini bersifat sahih. Hal ini didasarkan pada nilai pada r-hitung (correcteditem correlation) lebih besar dari nilai r-tabel $(0,32)$

Tabel 4. Tabel Kesahihan

\begin{tabular}{|lr|} 
& Corrected Item-Total Correlation \\
\hline P1 &, 448 \\
\hline P2 &, 414 \\
\hline P3 &, 417 \\
\hline P4 &, 515 \\
\hline P5 &, 742 \\
\hline P6 &, 659 \\
\hline P7 &, 580 \\
\hline P8 &, 564 \\
\hline P9 &, 700 \\
\hline P10 &, 635 \\
\hline P11 &, 649 \\
\hline P12 &, 721 \\
\hline P13 &, 669 \\
\hline P14 &, 394 \\
\hline
\end{tabular}

Sumber: data primer dengan SPSS $24, \mathrm{n}=38$

\section{Uji Normalitas}

Berdasarkan tampilan gambar Histogram di bawah, dapat dijelaskan bahwa gambar membentuk lonceng yang menjelaskan juga bahwa data berdistribusi normal. Begitu juga dengan gambar pada P-Plot yang juga menjelaskan data masih berdistribusi normal karena berada di sepanjang garis diagonal.

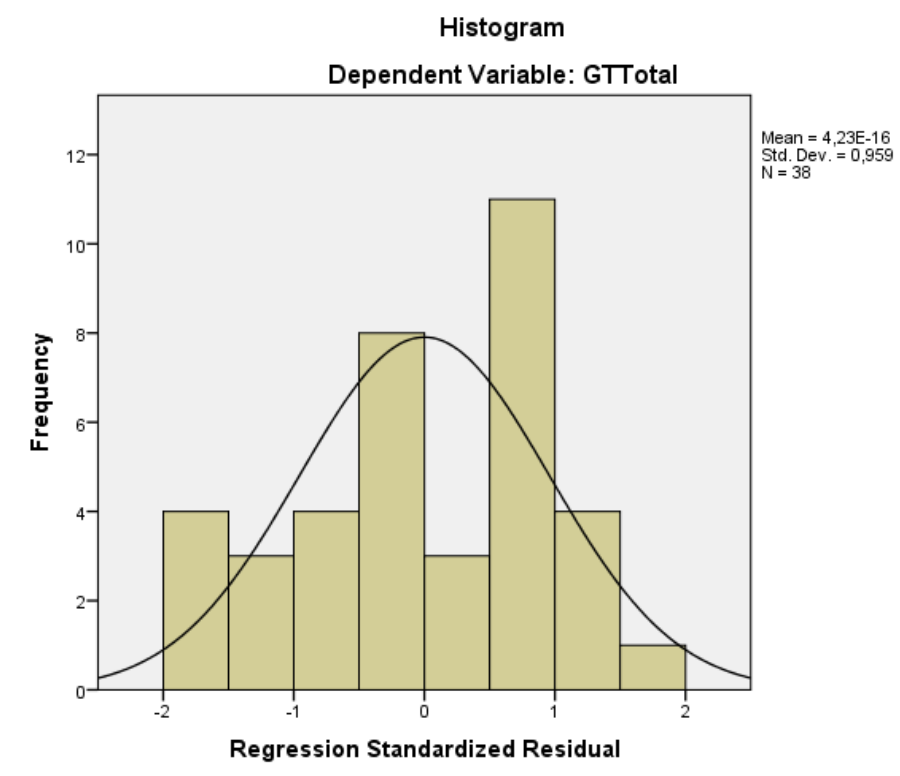

Gambar 2. Histogram - Normalitas

Sumber: data primer dengan SPSS $24, \mathrm{n}=38$ 


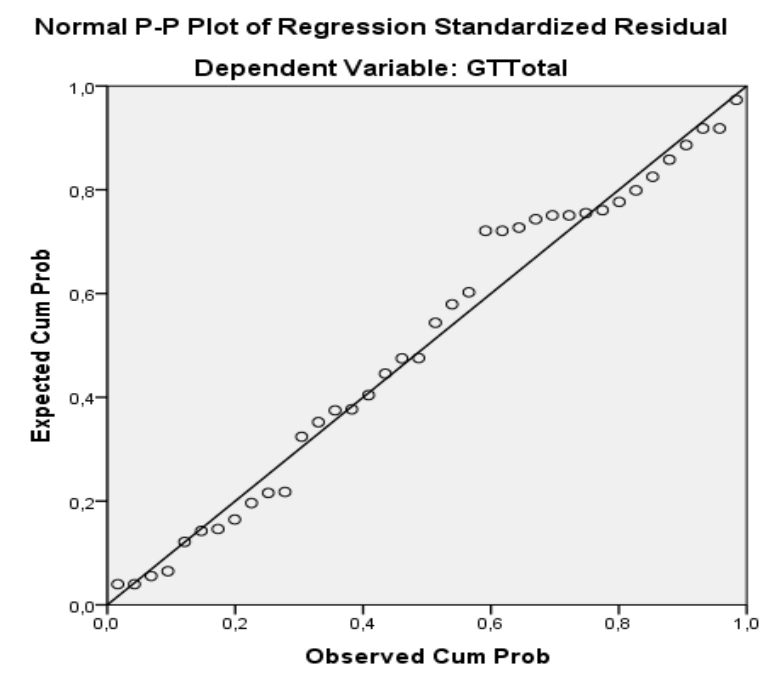

Gambar 3. P-Plot- Normalitas

Sumber: data primer dengan SPSS $24, \mathrm{n}=38$

\section{Uji Multikolineritas}

Uji multikolinieritas menjelaskan hubungan antar peubah dalam model regresi berganda. Tabel di bawah menjelaskan bahwa tidak terjadi gejala multikolinieritas. Hal ini didasarkan pada nilai TOL yang berada di atas 0,1 dan nilai VIF yang berada di bawah 10 .

Tabel 5. Tabel Gejala Multikolinieritas

Collinearity Statistics

\begin{tabular}{llr|r} 
Model & & Tolerance & \multicolumn{1}{c}{ VIF } \\
\hline 1 & (Constant) & & \\
\cline { 2 - 4 } & KMTotal &, 713 & 1,403 \\
\cline { 2 - 4 } & KRTotal &, 522 & 1,915 \\
\cline { 2 - 4 } & KPRTotal &, 573 & 1,744 \\
\hline
\end{tabular}

Sumber: data primer dengan SPSS $24, \mathrm{n}=38$

\section{Uji Heteroskedastisitas}

Pada gambar scatterplot di bawah dapat dijelaskan bahwa titik-titik menyebar di atas dan di bawah atau di sekitar angka 0 , sehingga dapat dikatakan bahwa tidak terjadi gejala heteroskedastisitas.

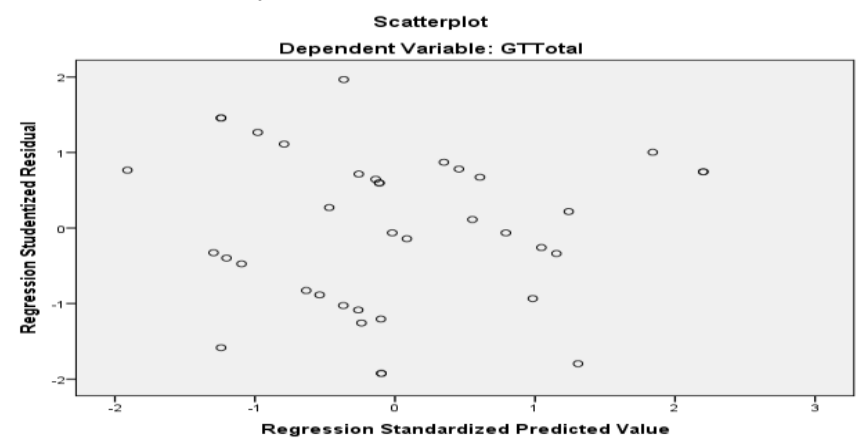

Gambar 3. Scatterplot

Sumber: data primer dengan SPSS $24, \mathrm{n}=38$ 


\section{Koefisien Determinasi}

Tabel model summary di bawah menunjukkan koefisien determinasi sebesar 0,358 atau sebesar $35,8 \%$. Angka ini menjelaskan bahwa Kualitas Petugas Restoran,
Kualitas Makanan, dan Kualitas Restoran memberikan pengaruh terhadap Getok Tular sebesar $35,8 \%$ atau sisanya sebesar $64,2 \%$ dipengaruhui oleh faktor-faktor lain diluar penelitian ini.

Tabel 5. Tabel Gejala Multikolinieritas

\begin{tabular}{|c|c|c|c|c|}
\hline \multirow[b]{2}{*}{ Model } & \multicolumn{4}{|c|}{ Model Summary } \\
\hline & $\mathrm{R}$ & R Square & $\begin{array}{c}\text { Adjusted R } \\
\text { Square } \\
\end{array}$ & $\begin{array}{l}\text { Std. Error of the } \\
\text { Estimate }\end{array}$ \\
\hline 1 &, $598^{\mathrm{a}}$ & ,358 & ,301 & 1,71870 \\
\hline
\end{tabular}

a. Predictors: (Constant), KPRTotal, KMTotal, KRTotal

b. Dependent Variable: GTTotal

Sumber: data primer dengan SPSS $24, \mathrm{n}=38$

\section{Uji Hipotesis}

Nilai sig pada tabel ANOVA di bawah menunjukkan angka 0,02 (lebih kecil dari 0,05) yang menjelaskan bahwa Getok Tular dipengaruhi secara simultan oleh Kualitas Petugas Restoran, Kualitas Makanan dan Kualitas Restoran.

Tabel 6. Tabel Uji Simultan

\begin{tabular}{|c|c|c|c|c|c|c|}
\hline \multicolumn{7}{|c|}{$\mathbf{A N O V A}^{\mathrm{a}}$} \\
\hline Model & & Sum of Squares & df & Mean Square & $\mathrm{F}$ & Sig. \\
\hline \multirow[t]{3}{*}{1} & Regression & 55,908 & 3 & 18,636 & 6,309 &, $002^{\mathrm{b}}$ \\
\hline & Residual & 100,434 & 34 & 2,954 & & \\
\hline & Total & 156,342 & 37 & & & \\
\hline
\end{tabular}

a. Dependent Variable: GTTotal

b. Predictors: (Constant), KPRTotal, KMTotal, KRTotal

Sumber: data primer dengan SPSS24, $n=38$

Tabel 7. Tabel Uji Parsial Coefficients $^{\mathrm{a}}$

\begin{tabular}{|c|c|c|}
\hline \multicolumn{2}{|c|}{ Model } & \multirow{2}{*}{$\begin{array}{l}\text { Sig. } \\
\quad 109\end{array}$} \\
\hline 1 & (Constant) & \\
\hline & KMTotal &, 542 \\
\hline & KRTotal & ,068 \\
\hline & KPRTotal & ,209 \\
\hline
\end{tabular}

Nilai sig pada tabel Coeffcient di bawah menunjukkan angka masing-masing peubah lebih besar dari 0,05 yang menjelaskan bahwa
Getok Tular tidak dipengaruhi secara parsial oleh Kualitas Petugas Restoran, Kualitas Makanan dan Kualitas Restoran. 


\section{SIMPULAN}

Berdasarkan analisis di atas dapat disimpulkan penelitian ini sebagai berikut:

1. Uji secara parsial pada faktor Getok Tular ternyata tidak dipengaruhi oleh faktor Kualtas Makanan. Hal ini memberikan indikasi bahwa restoran berbentuk waralaba yang sudah terkenal seperti KFC, Mc Donald, Burger King dan sebagainya kualitas bukan lagi menjadi faktor utama dalam membentuk getok tular. Hal ini juga memungkinkan untuk dijelaskan bahwa pengaruh merek restoran waralaba yang sudah memiliki nama, makanan yang disajikan akan tetap diterima oleh pembeli. Getok tular oleh berdasarkan hasil ini bukan dibentuk oleh kualitas makanan di persepsi pembeli.

2. Uji secara parsial pada faktor Getok Tular ternyata juga tidak dipengaruhi oleh faktor Kualitas Petugas Restoran. Hal ini memberikan indikasi bahwa restoran waralaba sudah diketahui memiliki standar sistem layanan, salah satunya petugas restoran. Prima atau kurangnya layananan yang diberikan oleh petugas restoran waralaba mungkin hanya membentuk kepuasan pembeli namun tidak mempengauhi getok tular secara langsung.

3. Uji secara parsial pada faktor Getok Tular tidak dipengaruhi oleh Kualitas Restoran. Restoran waralaba seperti yang dijelaskan sebelumnya memiliki standar sistem pelayanan, termasuk salah satunya desain dan tata letak interior dan eksterior restoran. Hal ini dapat diindikasikan sudah dapat diketahui dan disadari oleh banyak pengunjung, termasuk responden dalam penelitian ini. Hal ini memberikan dampak bahwa faktor tersebut tidak memberikan dampak pengaruh langsung pada getok tular.

4. Uji secara simultan pada faktor Getok Tular ternyata dipengaruhi oleh faktorfaktor Kualitas Makanan, Kualitas Petugas Restoran, dan Kualitas Restoran waralaba itu sendiri secara bersamaan. Hal ini menjelaskan bahwa ketika faktor-faktor tersebut bila digabungkan dapat memberikan dampak pengaruh pembentukan getok tular. Hal ini menjelaskan bahwa usaha restoran berbentuk waralaba tidak lagi dapat fokus pada faktor-faktor secara per bagian, namun harus memperhatikakan keseluruhan faktor secara bersamaan.

\section{SARAN}

Berdasarkan simpulan di atas, saran pada penelitian ini adalah pada faktor kualitas makanan, kualitas petugas, dan kualitas tampilan restoran, usaha restoran waralaba dapat membuat voting dan komentar atas makanan pada saat pengunjung selesai menyantap makanan yang dipesan, kualitas petugas restoran, dan kualitas restoran. Sistem ini menggunakan aplikasi yang terintegrasi dengan database usaha restoran waralaba tersebut. Sistem ini sudah banyak digunakan pada situs-situs ataupun aplikasi-aplikasi review berbasis daring. Pembeli yang tidak makan di tempat (take away) pun memungkinkan untuk ikut terlibat. Hal ini dapat membantu usaha restoran waralaba tersebut untuk membentuk dan menyebar luaskan kuliatas makanan, kualitas petugas restoran, dan kualitas tampilan restoran yang ada di restoran waralaba tersebut.

\section{DAFTAR PUSTAKA}

beritasatu. (2012, November 1). Bisnis Waralaba Dinilai Paling Cepat Tumbuhkan Wirausaha. Diakses pada Januari 19, 2018, from http://id.beritasatu.com:

http://id.beritasatu.com/home/bisniswaralaba-dinilai-paling-cepattumbuhkan-wirausaha/47959

beritasatu. (2017, September 5). Sektor Mamin Sumbang $80 \%$ Omzet Waralaba. Diakses pada Januari 19, 2018, from www.id.beritasatu.com: http://id.beritasatu.com/home/sektormamin-sumbang-80-omzetwaralaba/164856

BPS. (2014, Juni 2). Perkembangan Usaha Restoran/Rumah Makan Berskala Menengah dan Besar 2007-2012. Diakses pada Januari 19, 2018, from 
http://www.kemenpar.go.id:

http://www.kemenpar.go.id/userfiles/fi le/E_1\%20Perkembangan\%20Usaha\% 20Restoran\%20-

\%20RM\%20Besar\%20dan\%20Menen gah\%202008\%20-\%202012.pdf

Bujisic, M., Hutchinson, J., \& Parsa, H. (2014). The effects of restaurant quality attributes on customer behavioral intentions. International Journal of Contemporary Hospitality Management, 26(8), 1270-1291.

Faizal, M. (2017, November 7). Industri Makanan dan Minuman Kontributor Terbesar PDB Manufaktur. Diakses pada Januari 19, 2018, from www.ekbis.sindonews.com: https://ekbis.sindonews.com/read/1255 346/34/industri-makanan-danminuman-kontributor-terbesar-pdbmanufaktur-1510057336

Fauzi, A. (2017, Maret 11). Menkop Sebut Rasio Wirausaha Terus Meningkat. Diakses pada Januari 19, 2018, from kompas.com:

https://ekonomi.kompas.com/read/201 7/03/11/191200526/menkop.sebut.rasi o.wirausaha.terus.meningkat

Ha, J., \& Jang, S. (2010). Effects of service quality and food quality: the moderating role of atmospherics in an ethnic restaurant segment. International Journal of Hospitality Management, 29(3), 520-529.

Jalilvand, M. R., Salimipour, S., Elyasi, M., \& Mohammadi, M. (2017). Factors influencing word of mouth behaviour in the restaurant industry. Marketing Intelligence \& Planning, 35(1), 81110.

Jalilvand, M., Samiei, N., Dini, B., \& Yaghoubi. (2012). Examining the structural relationships of electronic word of mouth, destination image, tourist attitude toward destination and travel intention: an integrated approach. Journal of Destination Marketing Management, 1(1-2), 134143.

Jeong, E., \& Jang, S. (2011). Restaurant experiences triggering positive electronic word-of-mouth (eWOM) motivations. International Journal of Hospitality Management, 30(2), 356366.
Julianto, P. A. (2017, April 5). Perguruan Tinggi Harus Lahirkan Banyak Wirausaha Baru. Diakses pada Januari 19, 2018, from kompas.com: https://ekonomi.kompas.com/read/201 7/04/05/190830426/perguruan.tinggi.h arus.lahirkan.banyak.wirausaha.baru

Kemenpar. (2014, Juni 2). Perkembangan Usaha Restoran/ Rumah Makan Berskala Menengah dan Besar Menurut Provinsi. Diakses pada Januari 19, 2018, from http://www.kemenpar.go.id:

http://www.kemenpar.go.id/userfiles/fi le/E_2\%20Perkembangan\%20Usaha\% 20Restoran\%20-

\%20RM\%20Besar\%20dan\%20Menen gah\%20mnrt\%20Provinsi\%202008\%2 0-\%202012.pdf

Kemenpar. (2014, Juni 2). Statistik Usaha Restoran. Diakses pada Januari 19, 2018, from http://www.kemenpar.go.id:

http://www.kemenpar.go.id/userfiles/fi le/E_1\%20Perkembangan\%20Usaha\% 20Restoran\%20\%20RM\%20Besar\%20dan\%20Menen gah\%202008\%20-\%202012.pdf

Kurniawan, A. (2017, November 25). Industri Mamin Diramal Jadi Andalan Penopang Ekonomi Nasional. Diakses pada Januari 19, 2018, from www. ekbis.sindonews.com:

https://ekbis.sindonews.com/read/1260 436/34/industri-mamin-diramal-jadiandalan-penopang-ekonomi-nasional1511535822

Lloyd, N., Henry, J., \& Thyne, M. (2011). Do passengers listen to their crew? The use of word-of-mouth recommendations on board a cruise ship. Journal of Hospitality and Tourism Management, 18(1), 88-94.

Meng, J., \& Elliott, K. (2008). Predictors of relationship quality for luxury restaurants. Journal of Retailing and Consumer Services, 15(6), 18-22.

Namkung, Y., \& Jang, S. (2007). Does food quality really matter in restaurants? Its impact on customer satisfaction and behavioral intentions. Journal of Hospitality \& Tourism Research, 31(3), 387-410.

Ryu, K., \& Han, H. (2010). Influence of the quality of food, service, and physical 
environment on customer satisfaction and behavioral intention in quickcasual restaurants: moderating role of perceived price. Journal of Hospitality \& Tourism Research, 34(3), 310-329.

Vesel, P., \& Zabkar, V. (2009). Managing customer loyalty through the mediating role of satisfaction in the DIY retail loyalty program. Journal of Retailing and Consumer Services, 16(5), 396406.

Yasa, A. (2018, Februari 22). Bisnis Waralaba: Pertumbuhan Usaha Masih akan Ngebut Tahun Ini. Diakses pada
Februari 25, 2018, from http://industri.bisnis.com:

http://industri.bisnis.com/read/201802 22/12/741801/bisnis-waralabapertumbuhan-usaha-masih-akanngebut-tahun-ini

Yim, E., Lee, S., \& Kim, W. (2014). Determinants of a restaurant average meal price: an application of the hedonic pricing model. International Journal of Hospitality Management, 39(1), 11-20. 